\title{
catalysts
}

ISSN 2073-4344

www.mdpi.com/journal/catalysts

Article

\section{Visible Light-Photocatalytic Activity of Sulfate-Doped Titanium Dioxide Prepared by the Sol-Gel Method}

\section{Hiromasa Nishikiori $^{1{ }^{*},}$, Maki Hayashibe ${ }^{1}$ and Tsuneo Fujii ${ }^{2}$}

1 Department of Environmental Science and Technology, Faculty of Engineering, Shinshu University, 4-17-1 Wakasato, Nagano 380-8553, Japan; E-Mail: mhayashibe@yahoo.com

2 Nagano Prefectural Institute of Technology, 813-8 Shimonogo, Ueda, Nagano 386-1211, Japan; E-Mail: fujii@pit-nagano.ac.jp

* Author to whom correspondence should be addressed; E-Mail: nishiki@shinshu-u.ac.jp; Tel.: +81-26-269-5536; Fax: +81-26-269-5531.

Received: 19 February 2013; in revised form: 18 March 2013 / Accepted: 21 March 2013 / Published: 8 April 2013

\begin{abstract}
Sulfate-doped $\mathrm{TiO}_{2}$ was prepared from sol-gel systems containing titanium alkoxide and sulfuric acid. The time needed for gelation of the systems was significantly reduced by ultrasonic irradiation. The doped sulfate was observed by FTIR and XPS measurements. Some sulfate ions remained in the $\mathrm{TiO}_{2}$ even after heating at $300-600{ }^{\circ} \mathrm{C}$. The UV and visible photocatalytic activities of the samples were confirmed by the degradation of trichloroethylene (TCE). The activity of the photocatalyst samples during the UV irradiation strongly depended on their crystallinities rather than their specific surface areas, i.e., adsorption ability. The degradation rate during the visible irradiation depended on both the adsorption ability and visible absorption of the photocatalyst samples. The visible absorption induced by the sulfate-doping was effective for the TCE degradation.
\end{abstract}

Keywords: titanium dioxide; sulfate doping; sulfuric acid; ultrasonic irradiation; photocatalyst

\section{Introduction}

Visible-light-driven photocatalysts are expected to be developed in order to utilize solar and household light for the degradation of pollutants or harmful compounds and water splitting [1]. $\mathrm{TiO}_{2}$ acts as a photocatalyst during irradiation by only UV light shorter than around $400 \mathrm{~nm}$ because it has a 
band gap energy of about $3.0 \mathrm{eV}[1,2]$. The preparation, structure, and activity of nonmetal-doped $\mathrm{TiO}_{2}$, e.g., $C$-, $N$-, or $S$-doped $\mathrm{TiO}_{2}$, have been investigated because it is prepared from general reagents and is readily available [1]. Visible-light responsive $\mathrm{TiO}_{2}$ photocatalysts have been prepared by wet-method $\mathrm{N}$-doping, i.e., the calcination of the hydrolysis products of titanium tetraisopropoxide or titanium salts by an aqueous $\mathrm{NH}_{3}$ solution [3-5]. It is important to prepare the visible-light-driven photocatalyst by simpler methods. One of the wet-methods, the sol-gel method, is also used to obtain uniform $\mathrm{TiO}_{2}$ nano-sized crystalline particles. The $N$-doped $\mathrm{TiO}_{2}$ can be prepared from the sol-gel precursor solution containing various nitrogen compounds, such as urea and an alkyl amine [6-9].

These preparation procedures for the $\mathrm{N}$-doped $\mathrm{TiO}_{2}$ are based on the technology to oxidize the reduced nitrogen species, such as $\mathrm{NH}_{3}$, with the titanium species. On the other hand, we prepared the $N$-doped $\mathrm{TiO}_{2}$ by the sol-gel method using a large amount of nitric acid as the nitrogen source [10,11] as Dong et al. previously reported [12]. A large amount of nitric acid was required because most of it evaporated during the heating process. Nitric acid, which is often used as an acid catalyst in the sol-gel process to prepare $\mathrm{TiO}_{2}[13,14]$, is the most oxidized form of nitrogen. Nitric acid was reduced during the preparation process of $\mathrm{TiO}_{2}$ and the resulting $\mathrm{NO}$ species was situated in the networks because it also acts as an oxidizer [10,11]. However, this method requires a low temperature at around room temperature and a long time of about 30 days to prepare the $\mathrm{TiO}_{2}$ precursor gel because a rapid sol-gel reaction causes evaporation of the nitric acid and rapid disassembly of the system. The $S$-doped $\mathrm{TiO}_{2}$ can also be prepared in the similar procedure using a nonvolatile acid, i.e., sulfuric acid $[15,16]$. The $S$-doping is easier than $N$-doping because sulfuric acid is only slightly evaporated or reduced during the sample preparation. The sol-gel transition at around room temperature allows the sulfate to be homogeneously doped into the $\mathrm{TiO}_{2}$ without any surfactants. This method requires a long time although refluxing and drying the sol at high temperature easily shorten the gelation time [15]. The sulfated $\mathrm{TiO}_{2}$ was prepared by sulfuric acid-treatment of $\mathrm{TiO}_{2}$ or $\mathrm{Ti}(\mathrm{OH})_{2}$ as previously reported [17-19]. This method allows the sulfate ions to be dispersed only on the particle surface. The sulfated $\mathrm{TiO}_{2}$ exhibited a high photocatalytic activity due to strong Brønsted acidic sites on the surface although they have no visible light-photocatalytic activity.

In this study, we shortened the time needed for gelation of the sol-gel system containing titanium alkoxide and sulfuric acid at low temperature by ultrasonic irradiation. Ultrasonic irradiation accelerates the sol-gel reaction because the violent agitation promotes the collision of the titanium alkoxide molecules and evaporation of the solvent. The resulting dry gel was crystallized by the heating. The sulfur species in the samples was observed from the FTIR and XPS measurements. The UV and visible photocatalytic activities of this sample were examined by the degradation of trichloroethylene (TCE).

\section{Results and Discussion}

\subsection{Characterization of the Photocatalysts}

The characteristics of the prepared photocatalyst samples are summarized in Table 1. Figure 1 shows the SEM images of the prepared photocatalyst samples. No particle shape was clearly observed in the unheated sample, S0, which should be amorphous (not shown). The particle size of all the 
samples except for Sample S0 was 10-30 nm. The particles of the S300 look agglomerated because they consisted of not only crystalline phases, but also amorphous phases having an agglomerating property [20]. The particle size did not significantly increase with an increase in the heating temperature. The XRD patterns for all the samples except for Sample S0 exhibited diffraction peaks that appeared at around $25.3^{\circ}, 37.8^{\circ}, 48.1^{\circ}, 53.9^{\circ}$ and $54.8^{\circ}$ as shown in Figure 2. These peaks coincided with the typical pattern of the anatase-type $\mathrm{TiO}_{2}$. The crystallite sizes were estimated from the strongest peaks at $25.3^{\circ}$ as shown in Table 1 . The specific surface area and TCE adsorption decreased with an increase in the crystalline size. The crystallite size increased with an increase in the heating temperature. However, the size of Sample S600 heated at $600{ }^{\circ} \mathrm{C}$ was smaller than that of Sample $\mathrm{T}$ heated at $500{ }^{\circ} \mathrm{C}$. This result indicated that sulfate ions inhibited the crystal growth of the $\mathrm{TiO}_{2}$. Sulfuric acid acts as a catalyst for the hydrolysis and accelerates the sol-gel reaction. However, in some cases, sulfuric acid also prevents the polymerization or crystallization because it remains in the samples. Hydrochloric acid is easily evaporated after promoting the rearrangement of the $\mathrm{TiO}_{6}$ octahedra.

Table 1. Characteristics of the prepared catalysts.

\begin{tabular}{cccccc}
\hline Sample & T & S0 & S300 & S400 & S600 \\
\hline crystallite size $/ \mathrm{nm}$ & $17 \pm 2$ & - & $5.4 \pm 0.3$ & $6.7 \pm 0.3$ & $11 \pm 1$ \\
specific surface area $/ \mathrm{m}^{2} \mathrm{~g}^{-1}$ & 86 & - & 155 & 120 & 98 \\
TCE adsorption $/ \mathrm{mol} \mathrm{g}^{-1}$ & $1.0 \times 10^{-5}$ & $9.5 \times 10^{-5}$ & $2.1 \times 10^{-5}$ & $1.6 \times 10^{-5}$ & $1.0 \times 10^{-5}$ \\
S/Ti ratio & 0 & 0.078 & 0.046 & 0.017 & 0.004 \\
\hline
\end{tabular}

Figure 1. SEM images of (a) Sample T; (b) Sample S300, and (c) Sample S600.
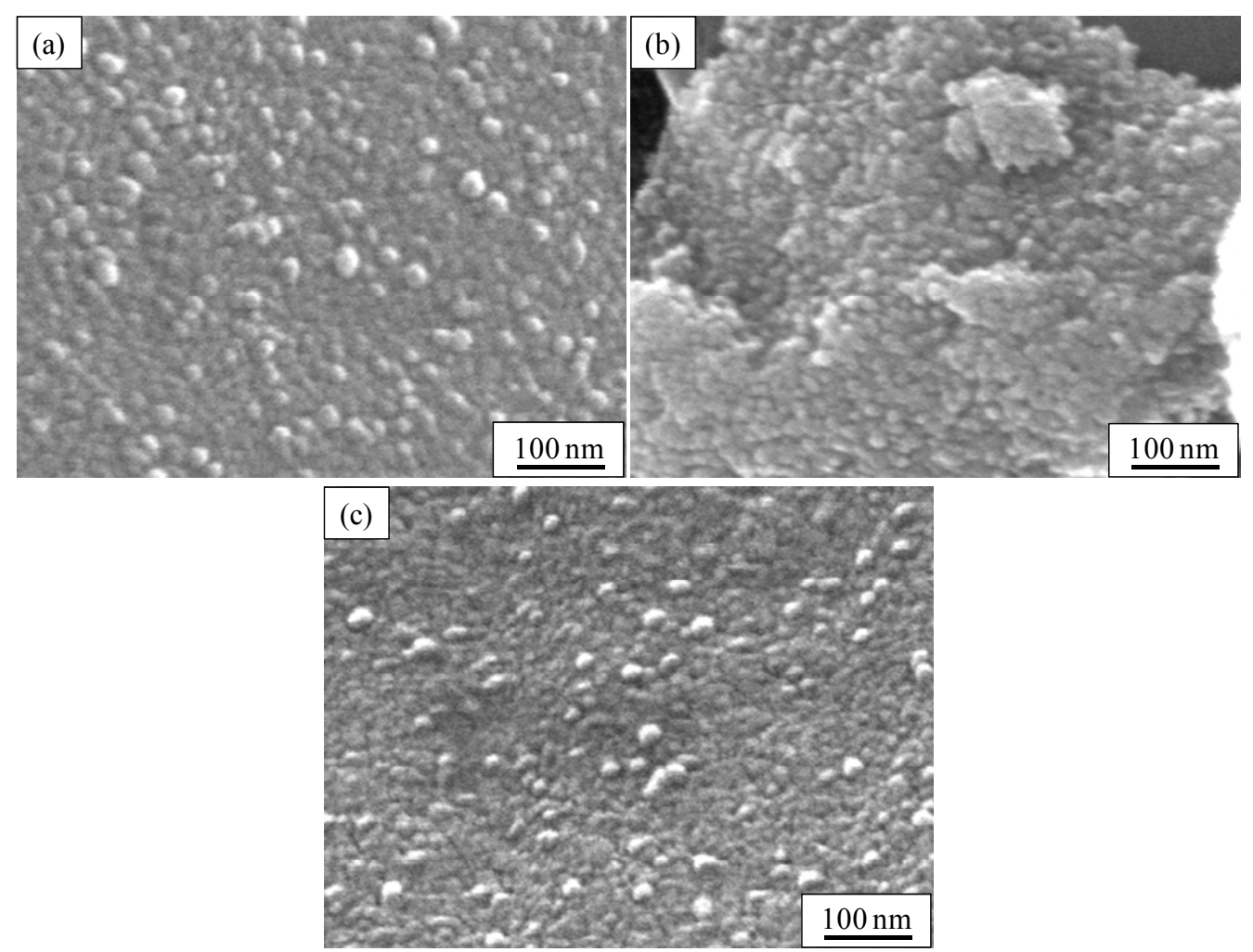
Figure 2. XRD patterns of (1) Sample T; (2) Sample S0; (3) Sample S300; (4) Sample S400 and (5) Sample S600.

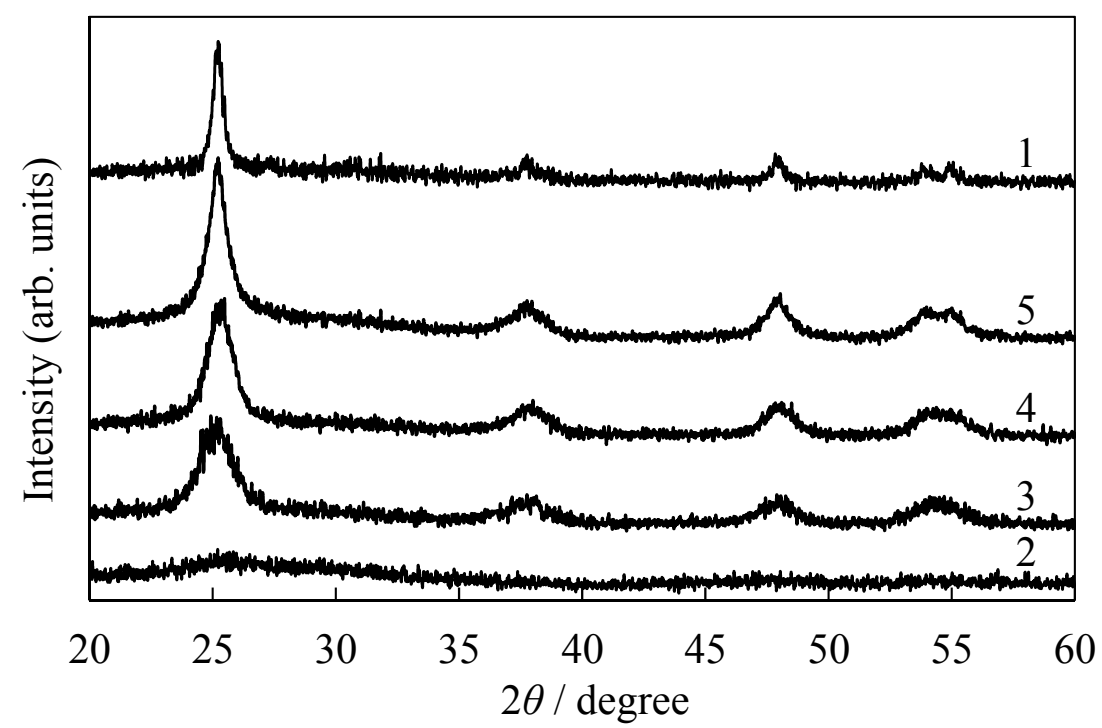

Figure 3 shows the UV-visible diffuse reflectance spectra of the prepared samples. The ordinate indicates the Kubelka-Munk function approximating the absorbance. The sulfate-doped $\mathrm{TiO}_{2}$ samples obviously exhibit a visible light absorption at around 400-420 nm, whereas the absorption edge of the normal $\mathrm{TiO}_{2}$ sample, $\mathrm{T}$, is located at around $370-380 \mathrm{~nm}$. Therefore, the sulfate-doped $\mathrm{TiO}_{2}$ probably more efficiently utilizes visible light than the normal $\mathrm{TiO}_{2}$. This result indicates that sulfur was definitely doped into the $\mathrm{TiO}_{2}$ and formed an impurity band above the valence band of the $\mathrm{TiO}_{2}$ due to the shifts in the absorption edge for the samples [1]. The impurity band formation can be explained by a mechanism similar to that of the NO-doped $\mathrm{TiO}_{2}$ with cationic $\mathrm{N}$ species [10,11]. The visible absorption was enhanced by heating at 300 and $400{ }^{\circ} \mathrm{C}$. The amorphous gel such as Sample S0 has the quasi-valence and conduction band structure with low density of state [21-23]. The UV absorption intensity depends on the state density of the bands in $\mathrm{TiO}_{2}$. The visible absorption also depends on the state density of the conduction band due to the electron transition from the impurity states to the conduction band. The visible absorption transition was enhanced by heating at 300 and $400{ }^{\circ} \mathrm{C}$ even though some sulfate ions had evaporated. The visible band decreased by heating at $600{ }^{\circ} \mathrm{C}$ due to significant sulfate evaporation.

Figure 4 shows the FTIR spectra of the samples. The spectrum of the dried gel, Sample S0, mainly has bands originating from the $\mathrm{OH}$-stretching (around $3400 \mathrm{~cm}^{-1}$ ), the $\mathrm{OH}$-bending of adsorbed water $\left(1630 \mathrm{~cm}^{-1}\right)$, tetrahedral TiO-stretching $\left(840 \mathrm{~cm}^{-1}\right)$ [24], and octahedral TiO-stretching $\left(560 \mathrm{~cm}^{-1}\right)$ [24-27]. In addition to these peaks, the sample exhibited the band for the SO-stretching of $\mathrm{SO}_{4}{ }^{2-}(1130$ and $\left.1050 \mathrm{~cm}^{-1}\right)[15,19,28,29]$. The sulfate-doped $\mathrm{TiO}_{2}$ is expected to exhibit an activity similar to that of the NO-doped $\mathrm{TiO}_{2}$. The sulfate or $\mathrm{S}^{6+}$ species was situated in the $S$-doped $\mathrm{TiO}_{2}$ prepared by the technology to oxidize the reduced sulfur species, such as thiourea, by the titanium species [28-31]. 
Figure 3. UV-visible diffuse reflectance spectra of (1) Sample T; (2) Sample S0; (3) Sample S300; (4) Sample S400 and (5) Sample S600 expressed by the Kubelka-Munk function approximating the absorbance.

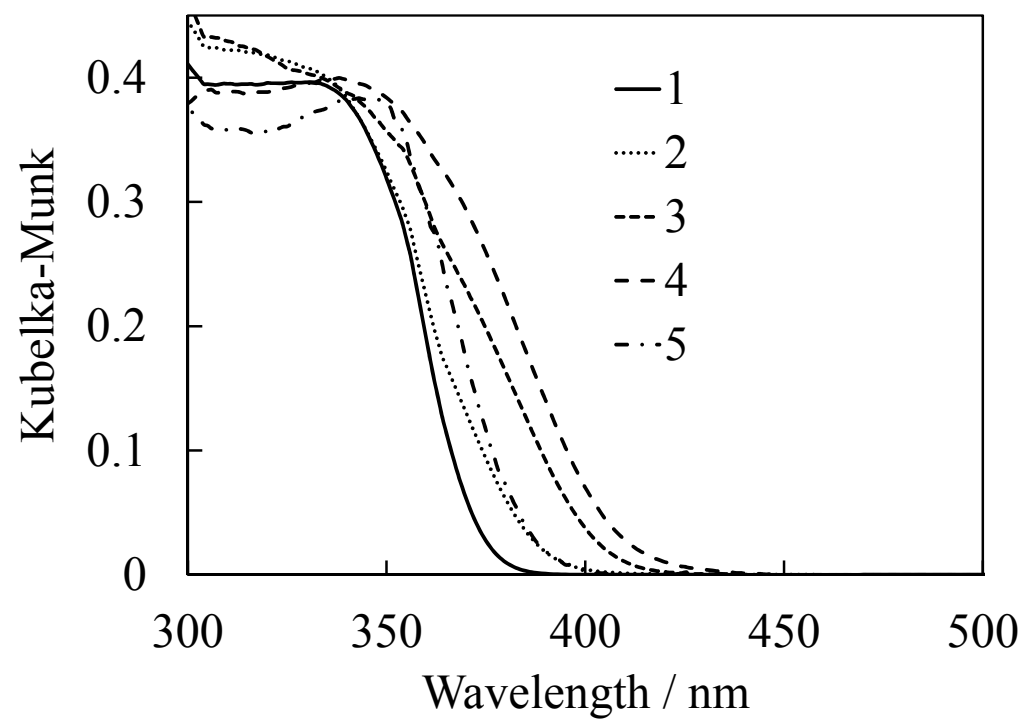

Figure 4. FTIR spectra of (1) Sample T; (2) Sample S0; (3) Sample S300; (4) Sample S400 and (5) Sample S600.

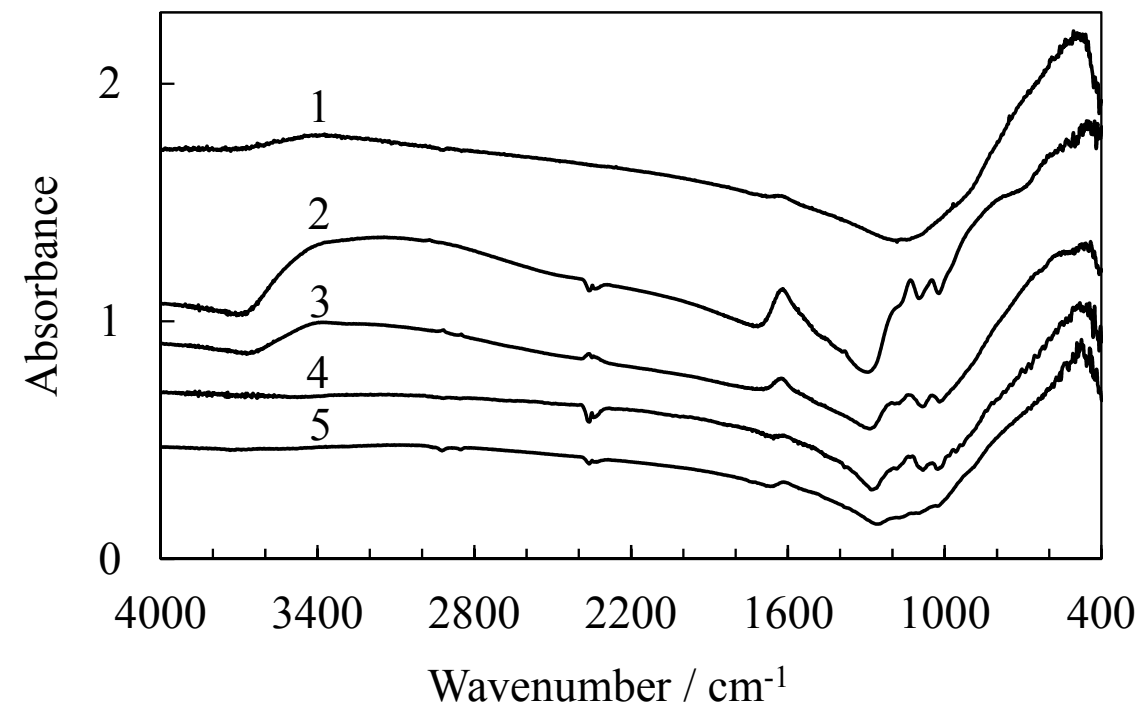

With increased heating, the bands due to the $\mathrm{OH}$ group, the adsorbed water, and the sulfate drastically decreased in their intensities. In addition to these observations, the relative intensity of the tetrahedral $\mathrm{TiO}$ band decreased and that of the octahedral $\mathrm{TiO}$ band increased. These results indicated that the $\mathrm{OH}$ groups are further condensed and that the resulting water molecules were evaporated by heating. These results also indicated that the visible absorption does not originate from the Ti complex with organic compounds because the organic compounds are hardly observed even in the FTIR spectrum of the dried gel before heating.

Figure 5 shows the XPS spectra relating the binding energy of the S $2 p$ electron for the samples. There was no peak in the spectrum of the sample, Sample T, prepared without sulfuric acid. In the 
samples prepared with sulfuric acid, peaks were clearly observed at $166-171 \mathrm{eV}$. This band is assigned to the $\mathrm{S}^{6+}$ in $\mathrm{SO}_{4}{ }^{2-}[19,28-31]$. The result of the XPS analysis supports the sulfate-doping into the $\mathrm{TiO}_{2}$ using our procedure. The atomic ratios, $\mathrm{S} / \mathrm{Ti}$, for the samples were also estimated by XPS analysis as shown in Table 1. The amount of the doped sulfate decreased with an increase in the heating temperature, similar to the result of the FTIR measurement.

Figure 5. S 2p XPS spectra of (1) Sample T; (2) Sample S0; (3) Sample S300; (4) Sample S400 and (5) Sample S600.

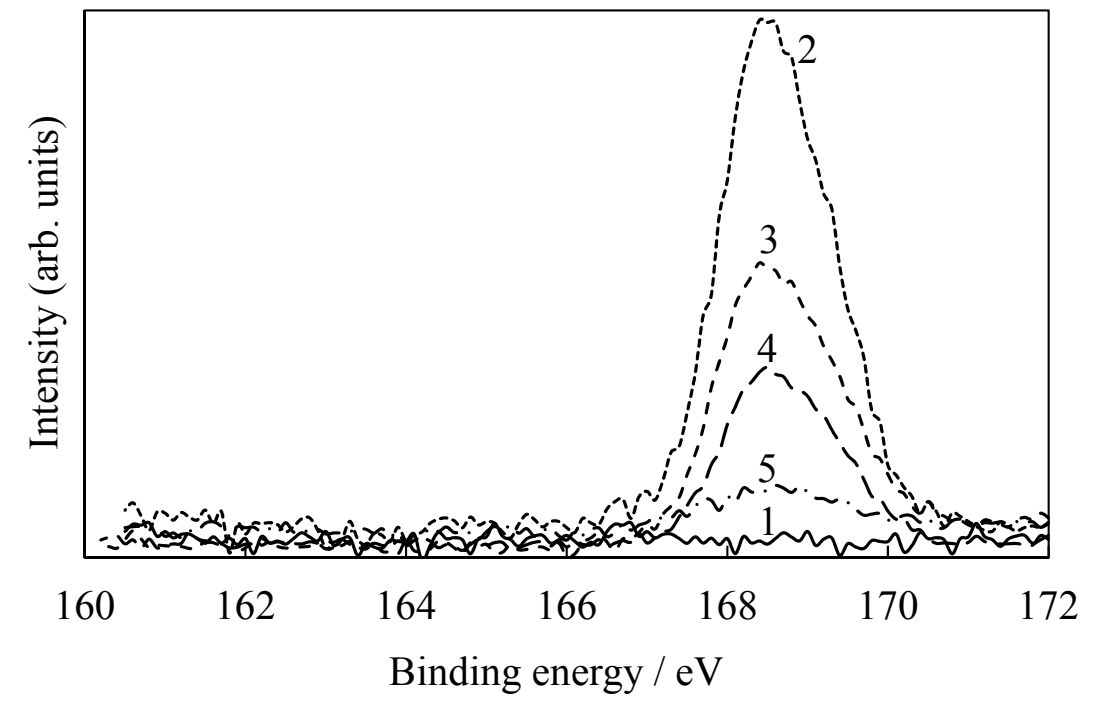

\subsection{Photocatalytic Degradation of TCE}

The photocatalytic degradation reactions of TCE were investigated using the prepared samples upon UV or visible irradiation. Three typical characteristic IR bands of TCE at $944 \mathrm{~cm}^{-1}$ (C-Cl stretching), $849 \mathrm{~cm}^{-1}$ (C-Cl stretching), and $783 \mathrm{~cm}^{-1}$ (C-H bending) rapidly decreased during the UV irradiation. In addition to these results, $\mathrm{CO}\left(2231-2066 \mathrm{~cm}^{-1}\right), \mathrm{CO}_{2}\left(2398-2280 \mathrm{~cm}^{-1}\right), \mathrm{COCl}_{2}\left(856 \mathrm{~cm}^{-1}\right), \mathrm{HCl}$ (3037-2723 $\mathrm{cm}^{-1}$ ), and dichloroacetyl chloride (DCAC) $\left(800\right.$ and $741 \mathrm{~cm}^{-1}$ ) were mainly produced during the reaction $[13,32-36]$. The degradation of TCE was confirmed by these IR measurements as reported in the literature $[10,11,13,33,36-40]$. During the visible irradiation, the TCE was degraded and $\mathrm{CO}, \mathrm{CO}_{2}, \mathrm{COCl}_{2}$, and $\mathrm{HCl}$ were also generated. However, no DCAC was found in this case, similar to the results reported in a previous paper [10,11,36].

The time course of the relative amounts of TCE and each product were estimated by analyzing their FTIR spectra. Figure 6 shows the time course of the relative concentration of TCE estimated from the IR absorbance at $944 \mathrm{~cm}^{-1}$. The degradation kinetics of TCE was influenced by the complex reaction process of its intermediate products even though the average degradation rates were estimated in order to compare the reactions using each photocatalyst shown in Table 2. The degradation rates should depend on the surface area of the samples. The degradation rates per unit surface area of the samples (250 $\mathrm{mg}$ ) are also shown there. TCE was degraded during the 5-10 min UV irradiation using the prepared samples, indicating that all the prepared samples functioned as a highly active photocatalyst. The order of the degradation rate during the UV irradiation was in the inverse order of the amount of the doped sulfate in the photocatalysts. The order of the degradation rate per unit surface area was also 
in the inverse order of the sulfate amount. The activity of the photocatalyst samples strongly depended on their crystallinity rather than their specific surface area because they were more different in their crystallite sizes than in the specific surface area.

Figure 6. Time course of trichloroethylene (TCE) concentration during the photocatalytic degradation of TCE using (1) Sample T; (2) Sample S300; (3) Sample S400 and (4) Sample S600 during (a) UV or (b) visible irradiation.

(a)

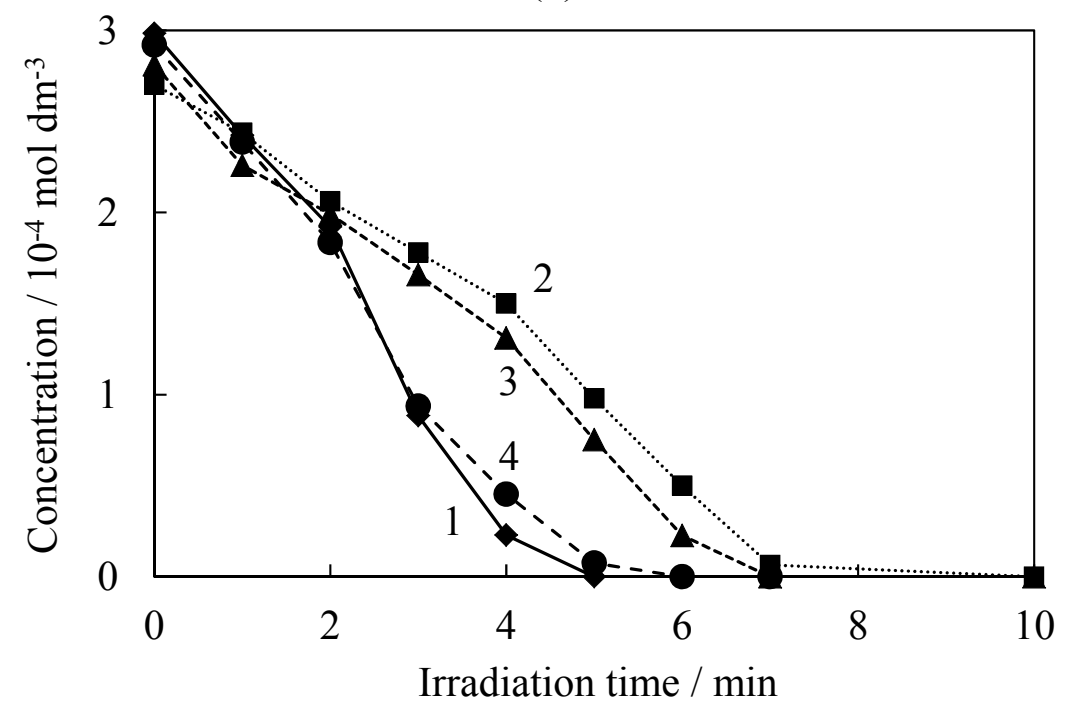

(b)

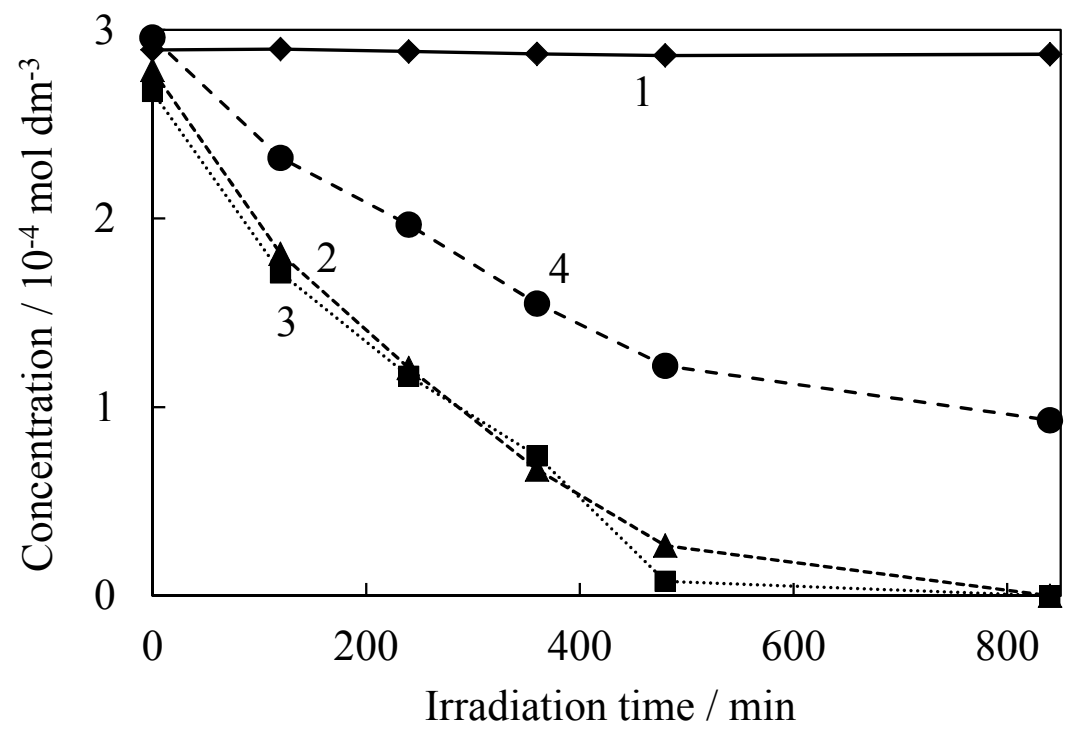

The normal $\mathrm{TiO}_{2}$ exhibited only a slight activity during the visible light irradiation. It took more than 800 min to degrade TCE using Samples S300, S400, and S600 during the visible light irradiation. The degradation rate was faster using Samples S300 and S400 than using Sample S600 because they had higher specific surface areas, i.e., a higher adsorption ability, and visible absorption than those of Sample S600. The visible absorption of the samples depends on the amount of the doped sulfate and the state density of the $\mathrm{TiO}_{2}$ bands. The degradation rate depended on both the adsorption ability and visible absorption of the photocatalyst samples. The order of the degradation rates per unit surface area 
of the samples was the same as that of the high visible absorption. These results indicated that the visible absorption induced by the sulfate-doping is effective in the degradation of TCE. A high activity requires not only an increase in the amount of the doped sulfate, but also control of the nanostructure of the photocatalyst particles.

Table 2. Average degradation rates of TCE using the prepared catalysts and those per unit surface area of the catalysts.

\begin{tabular}{|c|c|c|c|c|}
\hline Sample & $\mathbf{T}$ & S300 & S400 & S600 \\
\hline \multicolumn{5}{|l|}{ degradation rate $/ \mathrm{mol} \mathrm{dm}{ }^{-3} \mathrm{~min}^{-1}$} \\
\hline UV irradiation & 0.64 & 0.31 & 0.31 & 0.45 \\
\hline visible irradiation & $3.6 \times 10^{-5}$ & $5.1 \times 10^{-3}$ & $5.2 \times 10^{-3}$ & $2.4 \times 10^{-3}$ \\
\hline $\begin{array}{l}\text { degradation rate per unit surface area } \\
\qquad / \mathrm{mol} \mathrm{dm}^{-3} \min ^{-1} \mathrm{~m}^{-2}\end{array}$ & - & - & - & - \\
\hline UV irradiation & $3.0 \times 10^{-2}$ & $8.0 \times 10^{-3}$ & $1.0 \times 10^{-2}$ & $1.9 \times 10^{-2}$ \\
\hline visible irradiation & $1.7 \times 10^{-6}$ & $1.3 \times 10^{-4}$ & $1.7 \times 10^{-4}$ & $9.6 \times 10^{-5}$ \\
\hline
\end{tabular}

The changes in the degradation products during photocatalytic degradation of TCE using Sample T during UV irradiation and using Sample S400 during UV or visible irradiation were also examined. The absorbance at $944 \mathrm{~cm}^{-1}$ for TCE, at $2172 \mathrm{~cm}^{-1}$ for $\mathrm{CO}$, at $2358 \mathrm{~cm}^{-1}$ for $\mathrm{CO}_{2}$, at $1832 \mathrm{~cm}^{-1}$ for $\mathrm{COCl}_{2}$, at $2944 \mathrm{~cm}^{-1}$ for $\mathrm{HCl}$, and at $741 \mathrm{~cm}^{-1}$ for DCAC were plotted versus the irradiation time as shown in Figure 7. The concentrations of $\mathrm{CO}, \mathrm{CO}_{2}, \mathrm{COCl}_{2}$, and $\mathrm{HCl}$ gradually increased with a decrease in the TCE concentration during UV and visible irradiation. DCAC also initially increased and then decreased during UV irradiation, indicating that some TCE molecules were converted into $\mathrm{COCl}_{2}$ via DCAC similar to that for the previous photocatalytic degradation of TCE using $\mathrm{TiO}_{2}[10,11,13]$. This result clearly showed that the degradation of TCE was gradually followed by the formation of the intermediate products, $\mathrm{CO}, \mathrm{COCl}_{2}$, and DCAC, and the final products, $\mathrm{CO}_{2}$ and $\mathrm{HCl}$. It will take a longer time to complete the degradation.

The relationship between the concentrations of the produced $\mathrm{CO}_{2}$ and $\mathrm{COCl}_{2}$ using Sample $\mathrm{S} 400$ was found to be somewhat different from that using Sample T. A lower amount of $\mathrm{COCl}_{2}$ was produced using Sample S400 than using Sample T. The sulfated $\mathrm{TiO}_{2}$ surface with strong Brønsted and Lewis acidic sites promotes the adsorption of reactant and oxygen molecules and converts the adsorbed water molecules into the active hydroxyl groups [17,19] The present sulfate-doped $\mathrm{TiO}_{2}$ also exhibited a high photocatalytic activity due to such active surface. Some TCE can be directly decomposed into $\mathrm{CO}_{2}$ and $\mathrm{HCl}$ without producing DCAC or $\mathrm{COCl}_{2}$ on the surface.

$\mathrm{COCl}_{2}$ was directly produced from TCE without producing DCAC during the visible irradiation. In addition to this, higher amounts of $\mathrm{COCl}_{2}$ and $\mathrm{HCl}$ were obviously produced during the $\mathrm{UV}$ irradiation than during the visible irradiation. The smaller amounts of the chlorine compounds produced during the visible irradiation are due to recombination of the $\mathrm{Cl}$ radicals [36]. Some chlorine species are suggested to be tightly adsorbed on the catalyst and form a certain structure during the visible irradiation. On the other hand, the DCAC produced during the UV irradiation is adsorbed and forms a phosgene-like structure [36] on the catalyst and then desorbed into the gas phase. 
Figure 7. Time course of concentrations of (1) TCE and each product; (2) $\mathrm{CO}$; (3) $\mathrm{CO}_{2}$; (4) $\mathrm{COCl}_{2}$; (5) $\mathrm{HCl}$ and (6) DCAC, during photocatalytic degradation of TCE using (a) Sample T and (b,c) Sample S400 during (a,b) UV or (c) visible irradiation.

(a)

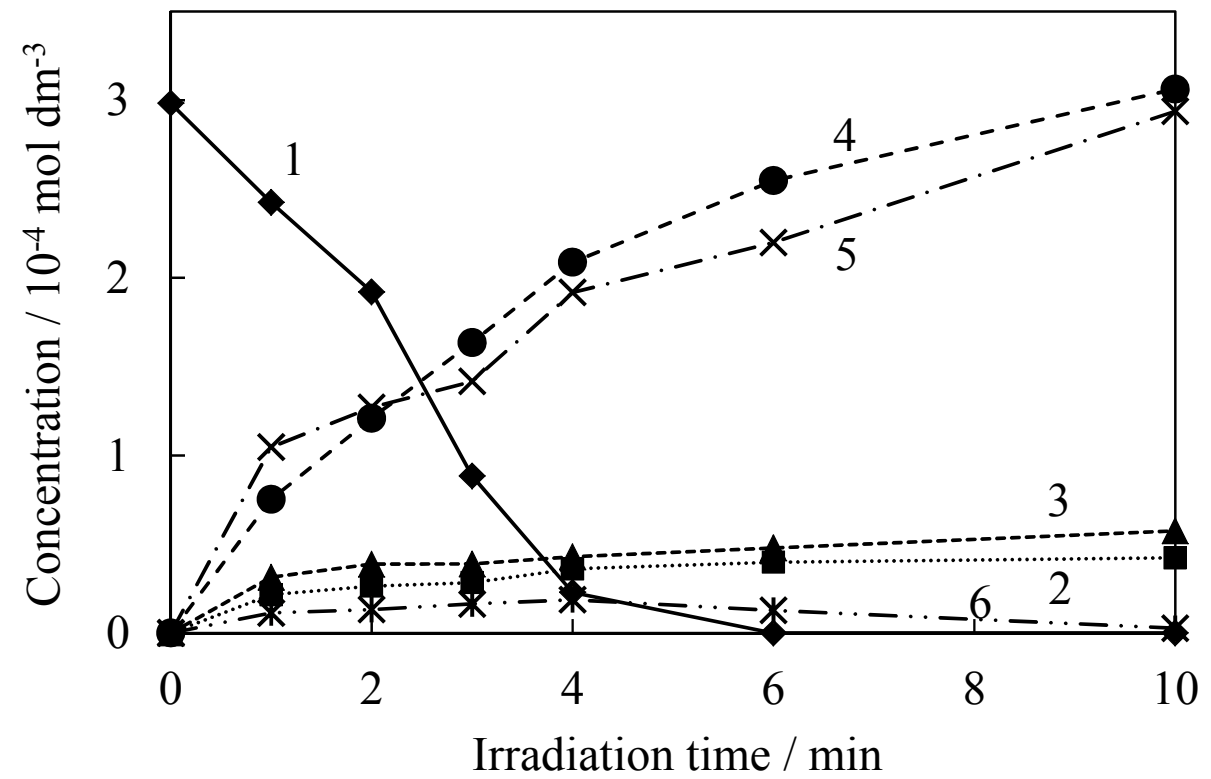

(b)

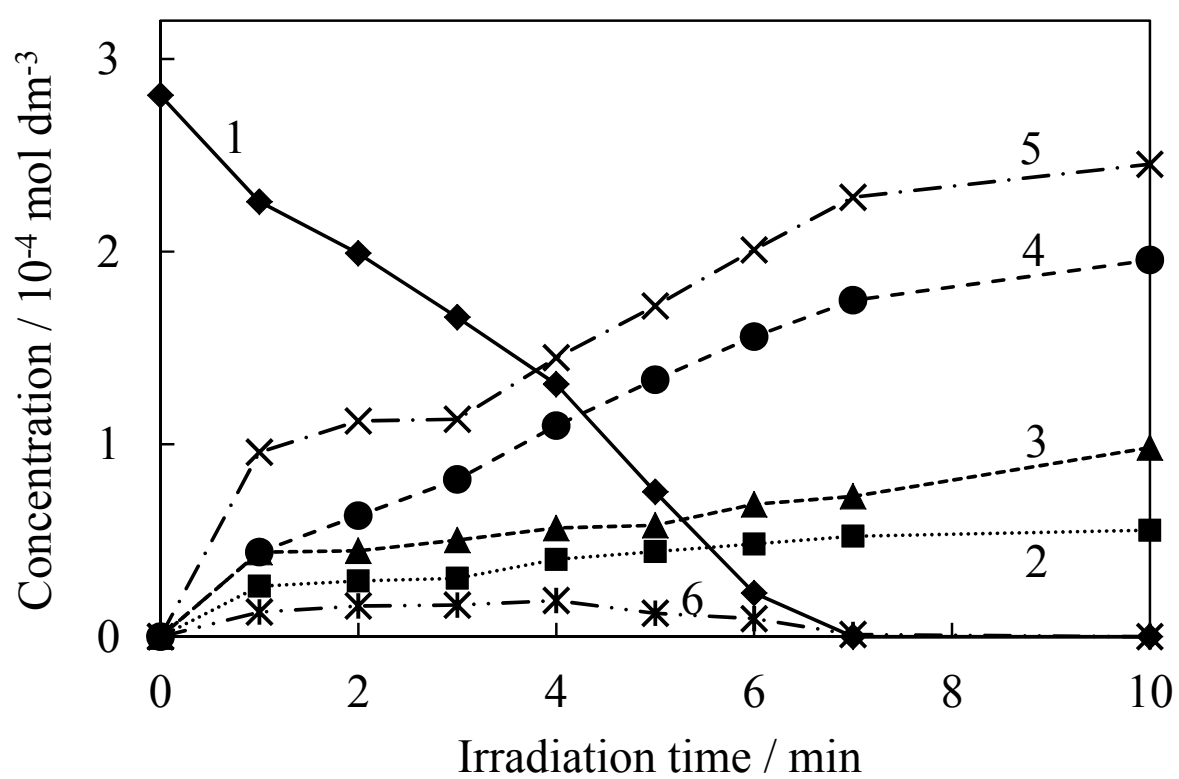


Figure 7. Cont.

(c)

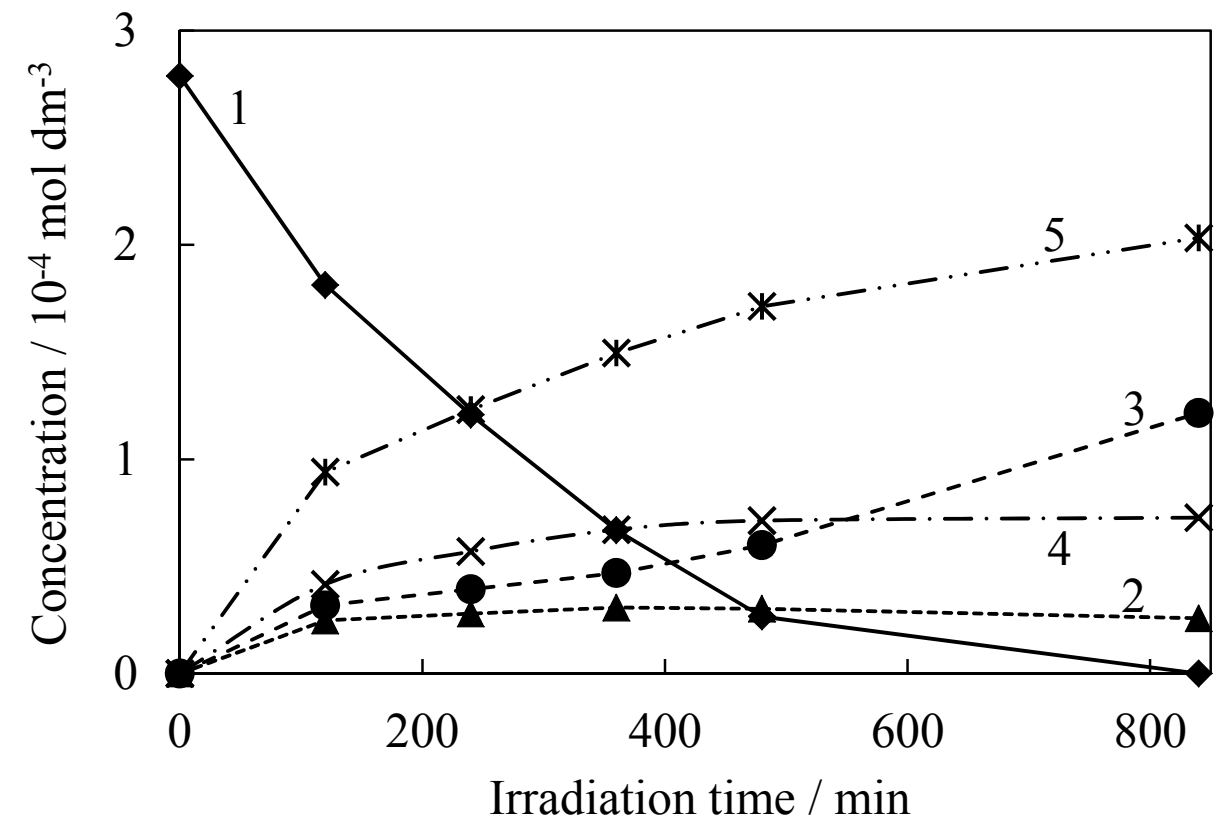

The duration of the photocatalytic activity of the sulfate-doped $\mathrm{TiO}_{2}$ during the UV and visible irradiations was investigated by repeated use of Sample S400. Figure 8 shows the time course of the relative concentration of TCE during the cycling of the photocatalytic degradation. The degradation of TCE was observed during the cycling of the UV and visible light irradiations for 10 and $840 \mathrm{~min}$, respectively. The TCE sample in the cell was replaced with a fresh one every cycle. TCE was almost degraded within $7 \mathrm{~min}$ by the UV irradiation over five times and in $840 \mathrm{~min}$ by the visible irradiation over three times. The sulfate-doped $\mathrm{TiO}_{2}$ is certain to be activated by not only the UV, but also visible light and to stably retain its photocatalytic activity during our experiments.

Figure 8. Time course of TCE concentration during the cycling of the photocatalytic degradation of TCE using Sample S400 during (a) UV or (b) visible irradiation.

(a)

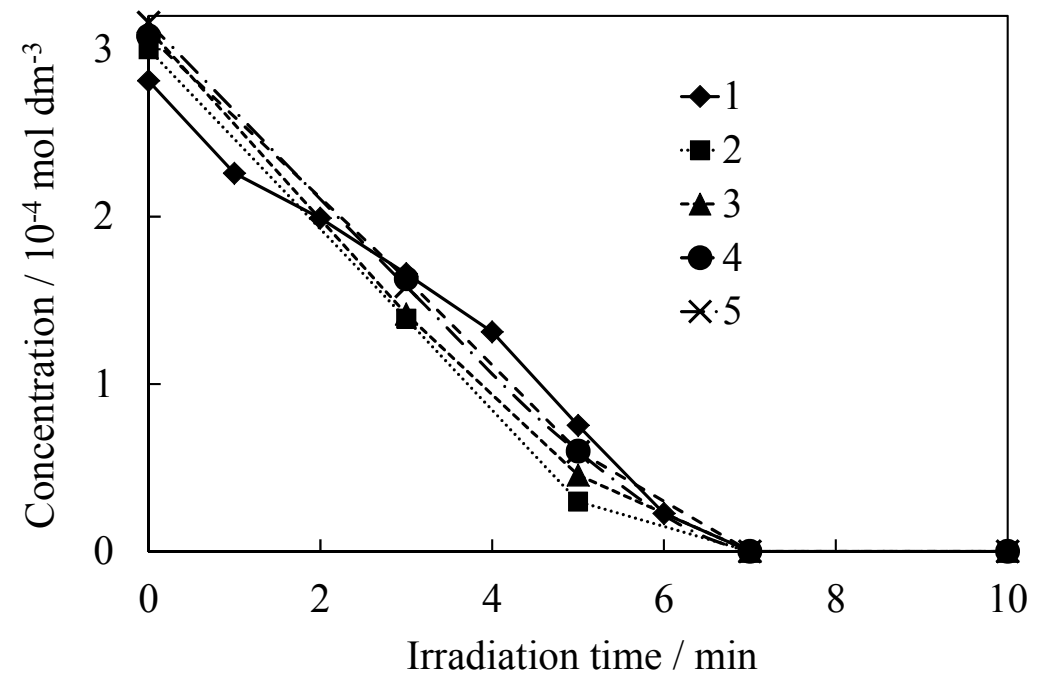


Figure 8. Cont.

(b)

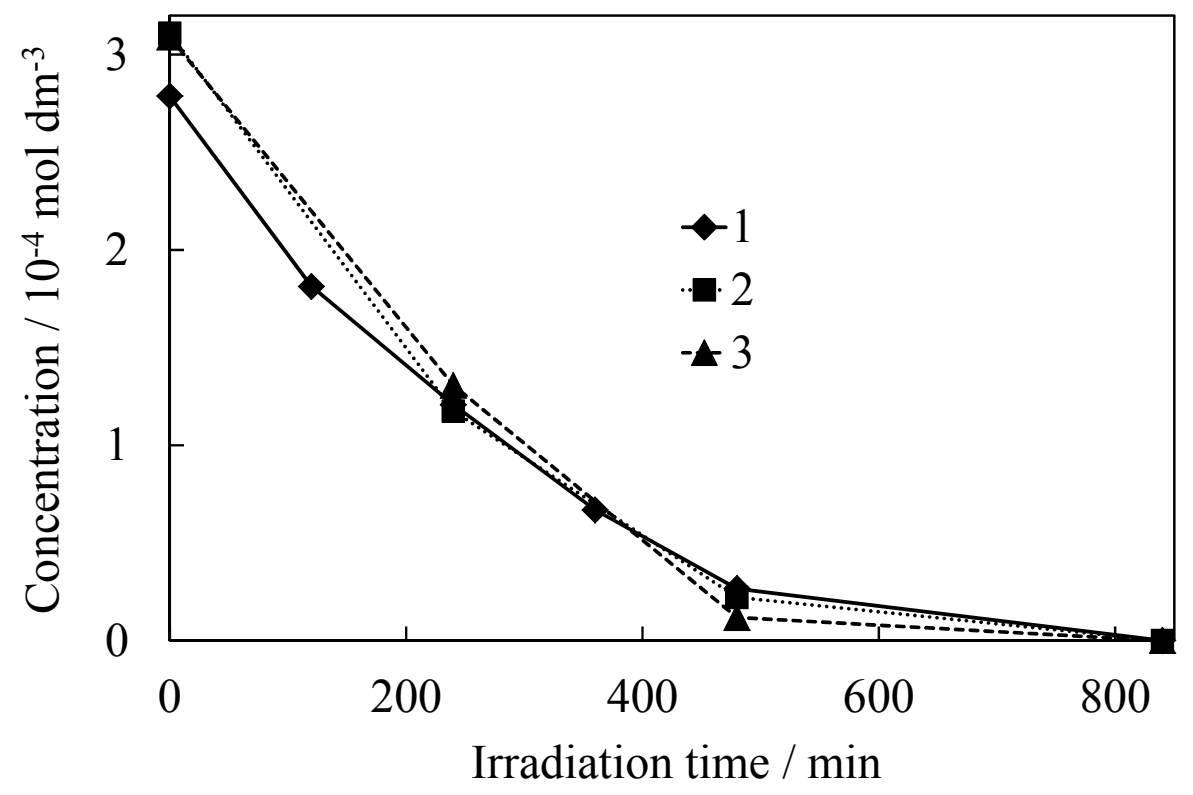

\section{Experimental Section}

\subsection{Materials}

Titanium tetraisopropoxide (TTIP), sulfuric acid (98\%), hydrochloric acid (35\%), TCE, and ethanol of S reagent grade were obtained from Wako Pure Chemical Industries (Osaka, Japan), and the dry nitrogen gas and dry air gas (ca. nitrogen $79 \%$ + oxygen $21 \%$ ) were obtained from Okaya Sanso (Okaya, Japan) and used without further purification. The water was deionized and distilled by a distiller (Yamato WG23, Tokyo Japan).

\subsection{Preparation of Photocatalysts}

The sol-gel system used to prepare the normal $\mathrm{TiO}_{2}$ consisted of $6.8 \mathrm{~cm}^{3}$ of TTIP, $40 \mathrm{~cm}^{3}$ of ethanol, and $1.0 \mathrm{~cm}^{3}$ of hydrochloric acid as a catalyst for the sol-gel reaction. The sol-gel systems to prepare the sulfate-doped $\mathrm{TiO}_{2}$ consisted of $6.8 \mathrm{~cm}^{3}$ of TTIP, $40 \mathrm{~cm}^{3}$ of ethanol, and $0.10 \mathrm{~cm}^{3}$ of sulfuric acid as the catalyst and sulfur source. TTIP was dropwise added to the mixture of the other materials in a glove box filled with dry nitrogen gas at ambient temperature. The systems were stirred during the addition, and then for an additional $15 \mathrm{~min}$. The reaction occurred during the ultrasonic irradiation. The gelation of all the systems was observed three days after starting the ultrasonic irradiation although it took more than 10 days without any ultrasonic irradiation. The resulting dry gel of the $\mathrm{TiO}_{2}$ precursor was heated at $500{ }^{\circ} \mathrm{C}$ for $3 \mathrm{~h}$ in order to prepare the anatase-type crystalline particles. This photocatalyst was labeled Sample T. The gel with sulfate was heated at 300, 400, or $600{ }^{\circ} \mathrm{C}$ for $3 \mathrm{~h}$. These samples prepared without heating and by heating at 300,400 , or $600{ }^{\circ} \mathrm{C}$ were labeled S0, S300, S400, and S600, respectively. 


\subsection{Characterization of Photocatalysts}

The prepared photocatalyst samples were characterized by SEM (Hitachi S-4000, Tokyo, Japan), XRD analysis using $\mathrm{CuK} \alpha$ radiation (Rigaku RINT2000, Tokyo, Japan), and XPS using AlK $\alpha$ radiation (ULVAC PHI 5600, Chigasaki, Japan). The size of the crystallites of each sample was estimated from the full-width at half-maximum of the $25.3^{\circ}$ peak in the XRD pattern using Sherrer's equation, $\mathrm{D}=0.9 \lambda / \beta \cdot \cos \theta$. The specific surface areas of the samples pretreated at $200{ }^{\circ} \mathrm{C}$ for $12 \mathrm{~h}$ were measured by the volumetric gas adsorption method using nitrogen gas (BEL Japan, BELSORP-mini, Toyonaka, Japan). The spectroscopic properties of the samples were analyzed by UV-visible diffuse reflectance spectroscopy (Shimadzu UV3150, Kyoto, Japan) and FTIR spectroscopy (Shimadzu FTIR8300, Kyoto, Japan). For the FTIR measurements, the gel and crystalline powder samples were pressed in $\mathrm{KBr}$ pellets.

\subsection{Photocatalytic Degradation of TCE}

Each photocatalyst sample of $250 \mathrm{mg}$ was placed in an infrared cell, which was made of Pyrex glass. Two plates of $\mathrm{KBr}$ single crystals were used as the infrared windows and were sealed by Teflon O-rings. The TCE gas diluted with dry air was injected into the infrared cell in which its final concentration was $3.2 \times 10^{-4} \mathrm{~mol} \mathrm{dm}^{-3}$. The cell was kept at ambient temperature until the adsorption of TCE had equilibrated. The adsorption abilities of the samples for the TCE were estimated from the concentrations after their adsorption equilibria by FTIR analysis. The degradation reaction of the TCE was carried out in the cell by near-UV light irradiation from a 4-W black light bulb (Toshiba FL4BLB, Tokyo, Japan) and visible light from a 150-W xenon lamp (Hamamatsu Photonics C2577, Hamamatsu, Japan) with a 420-nm cutoff filter. The FTIR spectra of the gas phase in the cell were obtained as a function of the light irradiation time. The changes in the TCE and product concentrations were determined during the TCE degradation using the prepared photocatalyst samples. We can assume that the chemical species that existed in the reaction cell are in equilibrium between the gas phase and the catalyst surface. Therefore, the decomposed species on the catalyst surface appear in the FTIR spectra.

\section{Conclusions}

The sulfate-doped $\mathrm{TiO}_{2}$ was prepared from the sol-gel systems containing titanium alkoxide and sulfuric acid. The time needed for gelation of the system was drastically reduced by ultrasonic irradiation. The crystallite size of the photocatalyst samples increased and their specific surface area, i.e., adsorption ability, decreased with an increase in the treatment temperature. The peak assigned to $\mathrm{SO}_{4}{ }^{2-}$ was observed by FTIR and XPS measurements in the prepared catalyst samples. A greater amount of the sulfate was placed in the $\mathrm{TiO}_{2}$ networks after heating at a lower temperature. The visible absorption was enhanced by heating at 300 and $400{ }^{\circ} \mathrm{C}$ due to an increase in the state density of the $\mathrm{TiO}_{2}$ conduction band even though some sulfate ions had evaporated. The visible band decreased by heating at $600{ }^{\circ} \mathrm{C}$ due to significant evaporation of the sulfate. The photocatalytic activity of the sulfate-doped $\mathrm{TiO}_{2}$ samples during the UV and visible irradiations was confirmed by the TCE degradation. The activity of the photocatalyst samples during the UV irradiation strongly depended on their crystallinities rather than on their adsorption ability because they were more different in their 
crystallite sizes than in their specific surface area. The degradation rate during the visible irradiation depended on both the adsorption ability and visible absorption of the photocatalyst samples. The visible absorption induced by the sulfate-doping was effective for the TCE degradation.

\section{Acknowledgments}

This work was supported by JSPS KAKENHI Grant Number 24550153.

\section{References}

1. Chatterjee, D.; Dasgupta, S. Visible light induced photocatalytic degradation of organic pollutants. J. Photochem. Photobiol. C 2005, 6, 186-205.

2. Fujishima, A.; Rao, T.N.; Tryk, D.A. Titanium dioxide photocatalysis. J. Photochem. Photobiol. C 2000, 1, 1-21.

3. Sato, S. Photocatalytic activity of $\mathrm{NO} x$-doped $\mathrm{TiO}_{2}$ in the visible light region. Chem. Phys. Lett. 1986, 123, 126-128.

4. Ihara, T.; Miyoshi, M.; Iriyama, Y.; Matsumoto, O.; Sugihara, S. Visible-light-active titanium oxide photocatalyst realized by an oxygen-deficient structure and by nitrogen doping. Appl. Catal. B 2003, 42, 403-409.

5. Subagio, D.P.; Srinivasan, M.; Lim, M.; Lim, T. Photocatalytic degradation of bisphenol-A by nitrogen-doped $\mathrm{TiO}_{2}$ hollow sphere in a vis-LED photoreactor. Appl. Catal. B 2010, 95, 414-422.

6. Gandhe, A.R.; Naik, S.P.; Fernandes, J.B. Selective synthesis of $N$-doped mesoporous $\mathrm{TiO}_{2}$ phases having enhanced photocatalytic activity. Microporous Mesoporous Mater. 2005, 87, 103-109.

7. Choi, H.; Antoniou, M.G.; Pelaez, M.; De la Cruz, A.A.; Shoemaker, J.A.; Dionysiou, D.D. Mesoporous nitrogen-doped $\mathrm{TiO}_{2}$ for the photocatalytic destruction of the cyanobacterial toxin microcystin-LR under visible light irradiation. Environ. Sci. Technol. 2007, 41, 7530-7535.

8. Jagadale, T.C.; Takale, S.P.; Sonawane, R.S.; Joshi, H.M.; Patil, S.I.; Kale, B.B.; Ogale, S.B. $N$-Doped $\mathrm{TiO}_{2}$ nanoparticle based visible light photocatalyst by modified peroxide sol-gel method. J. Phys. Chem. C 2008, 112, 14595-14602.

9. Ananpattarachai, J.; Kajitvichyanukul, P.; Seraphin, S. Visible light absorption ability and photocatalytic oxidation activity of various interstitial $N$-doped $\mathrm{TiO}_{2}$ prepared from different nitrogen dopants. J. Hazardous Mater. 2009, 168, 253-261.

10. Yokosuka, Y.; Oki, K.; Nishikiori, H.; Tatsumi, Y.; Tanaka, N.; Fujii, T. Photocatalytic degradation of trichloroethylene using $N$-doped $\mathrm{TiO}_{2}$ prepared by a simple sol-gel process. Res. Chem. Intermed. 2009, 35, 43-53.

11. Nishikiori, H.; Fukasawa, Y.; Yokosuka, Y.; Fujii, T. Nitrogen doping into titanium dioxide by the sol-gel method using nitric acid. Res. Chem. Intermed. 2011, 37, 869-881.

12. Dong, C.X.; Xian, A.P.; Ham, E.H.; Shang, J.K. Acid-mediated sol-gel synthesis of visible-light active photocatalysts. J. Mater. Sci. 2006, 41, 6168-6170.

13. Oki, K.; Tsuchida, S.; Nishikiori, H.; Tanaka, N.; Fujii, T. Photocatalytic degradation of chlorinated ethenes. Int. J. Photoenergy 2003, 5, 11-15. 
14. Oki, K.; Yamada, S.; Tsuchida, S.; Nishikiori, H.; Tanaka, N.; Fujii, T. Degradation and isomerization of 1,2-dichloroethenes by photocatalytic reactions. Res. Chem. Intermed. 2003, 29, 827-837.

15. Liu, Y.; Liu, J.; Lin, Y.; Zhang, Y.; Wei, Y. Simple fabrication and photocatalytic activity of $S$-doped $\mathrm{TiO}_{2}$ under low power LED visible light irradiation. Ceramics Int. 2009, 35, 3061-3065.

16. Han, C.; Pelaez, M.; Likodimos, V.; Kontos, A.G.; Falaras, P.; O’Shea, K.; Dionysiou, D.D. Innovative visible light-activated sulfur doped $\mathrm{TiO}_{2}$ films for water treatment. Appl. Catal. B 2011, 107, 77-87.

17. Muggli, D.S.; Ding, L. Photocatalytic performance of sulfated $\mathrm{TiO}_{2}$ and Degussa P-25 $\mathrm{TiO}_{2}$ during oxidation of organics. Appl. Catal. B 2001, 32, 181-194.

18. Noda, L.K.; de Almeida, R.M.; Gonçalves, N.S.; Probst, L.F.D.; Sala, O. $\mathrm{TiO}_{2}$ with a high sulfate content - thermogravimetric analysis, determination of acid sites by infrared spectroscopy and catalytic activity. Catal. Today 2003, 85, 69-74.

19. Wang, X.; Yu, J.C.; Liu, P.; Wang, X.; Su, W.; Fu, X. Probing of photocatalytic surface sites on $\mathrm{SO}_{4}{ }^{2-} / \mathrm{TiO}_{2}$ solid acids by in situ FT-IR spectroscopy and pyridine adsorption. J. Photochem. Photobiol. A 2006, 179, 339-347.

20. Maira, A.J.; Yeung, K.L.; Lee, C.Y.; Yue, P.L.; Chan, C.K. Size effects in gas-phase photo-oxidation of trichloroethylene using nanometer-sized $\mathrm{TiO}_{2}$ catalysts. J. Catal. 2000, 192, 185-196.

21. Nishikiori, H.; Tanaka, N.; Kitsui, T.; Fujii, T. Photocurrent observed in dye-doped titania gel. J. Photochem. Photobiol. A 2006, 179, 125-129.

22. Nishikiori, H.; Uesugi, Y.; Takami, S.; Setiawan, R.A.; Fujii, T.; Qian, W.; El-Sayed, M.A. Influence of steam treatment on dye-titania complex formation and photoelectric conversion property of dye-doped titania gel. J. Phys. Chem. C 2011, 115, 2880-2887.

23. Nishikiori, H.; Setiawan, R.A.; Miyamoto, K.; Sukmono, G.; Uesugi, Y.; Teshima, K.; Fujii, T. Photoinduced electron transport in dye-containing titania gel films. $R S C A d v$. 2012, 2 , 4258-4267.

24. Tarte, P. The Determination of Cation Co-cordination in Glasses by Infra-red Spectroscopy. In Physics of Non-Crystalline Solids; Prins, J.A., Ed.; North Holland: Amsterdam, The Netherlands, 1965; pp. 549-565.

25. Galzada, M.L.; Delolmo, L. Sol-gel processing by inroganic route to obtain a $\mathrm{TiO}_{2}-\mathrm{PbO}$ xerogel as ceramic precursor. J. Non-Cryst. Solids 1990, 121, 413-416.

26. Ben Amor, S.; Baud, G.; Besse, J.P.; Jacquet, M. Structural and optical properties of sputtered Titania films. Mater. Sci. Eng. 1997, 47, 110-118.

27. Castañeda, L.; Alonso, J.C.; Ortiz, A.; Andrade, E.; Saniger, J.M.; Bañuelos, J.G. Spray pyrolysis deposition and characterization of titanium oxide thin films. Mater. Chem. Phys. 2003, 77, 938-944.

28. Nam, S.; Kim, T.K.; Boo, J. Physical property and photo-catalytic activity of sulfur doped $\mathrm{TiO}_{2}$ catalysts responding to visible light. Catal. Today 2012, 185, 259-262.

29. Yang, G.; Yan, Z.; Xiao, T. Low-temperature solvothermal synthesis of visible-light-responsive S-doped $\mathrm{TiO}_{2}$ nanocrystal. Appl. Surface Sci. 2012, 258, 4016-4022.

30. Ohno, T.; Mitsui, T.; Matsumura, M. Photocatalytic activity of $S$-doped $\mathrm{TiO}_{2}$ photocatalyst under visible light. Chem. Lett. 2003, 32, 364-365. 
31. Nakahira, A.; Yokota, K.; Kubo, T.; Takahashi, M. Synthesis and characterization of S-doped $\mathrm{TiO}_{2}$ made by anodic oxidation of titanium in sulfuric acid. Chem. Lett. 2007, 36, 1318-1319.

32. Kim, J.S.; Itoh, K.; Murabayashi, M.; Kim, B.A. Pretreatment of the photocatalyst and the photocatalytic degradation of trichloroethylene in the gas-phase. Chemosphere 1999, 38, 2969-2978.

33. Amama, P.B.; Itoh, K.; Murabayashi, M. Photocatalytic oxidation of trichloroethylene in humidified atmosphere. J. Mol. Catal. A 2001, 176, 165-172.

34. Kang, M.; Lee, J.H.; Lee, S.H.; Chung, C.H.; Yoon, K.J.; Ogino, K.; Miyata, S.; Choung, S.J. Preparation of $\mathrm{TiO}_{2}$ film by the MOCVD method and analysis for decomposition of trichloroethylene using in situ FT-IR spectroscopy. J. Mol. Catal. A 2003, 193, 273-283.

35. Nakamura, R.; Tanaka, T.; Nakato, Y. Mechanism for visible light responses in anodic photocurrents at $N$-doped $\mathrm{TiO}_{2}$ film electrodes. J. Phys. Chem. B 2004, 108, 10617-10620.

36. Joung, S.K.; Amemiya, T.; Murabayashi, M.; Itoh, K. Mechanistic studies of the photocatalytic oxidation of trichloroethylene with visible-light-driven $N$-doped $\mathrm{TiO}_{2}$ photocatalysts. Chemistry 2006, 12, 5526-5534.

37. Jacoby, W.A.; Nimlos, M.R.; Blake, D.M.; Noble, R.D.; Koval, C.A. Products, intermediates, mass balances, and reaction pathways for the oxidation of trichloroethylene in air via heterogeneous photocatalysis. Environ. Sci. Technol. 1994, 28, 1661-1668.

38. Fan, J.; Yates, J.T., Jr. Mechanism of photooxidation of trichloroethylene on $\mathrm{TiO}_{2}$ : Detection of intermediates by infrared spectroscopy. J. Am. Chem. Soc. 1996, 118, 4686-4692.

39. Driessen, M.D.; Goodman, A.L.; Miller, T.M.; Zaharias, G.A.; Grassian, V.V. Gas-phase photooxidation of trichloroethylene on $\mathrm{TiO}_{2}$ and $\mathrm{ZnO}$ : Influence of trichloroethylene pressure, oxygen pressure, and the photocatalyst surface on the product distribution. J. Phys. Chem. B 1998, 102, 549-556.

40. Kim, J.S.; Itoh, K.; Murabayashi, M. Photocatalytic degradation of trichloroethylene in the gas phase over $\mathrm{TiO}_{2}$ sol-gel films: Analysis of products. Chemosphere 1998, 36, 483-495.

(C) 2013 by the authors; licensee MDPI, Basel, Switzerland. This article is an open access article distributed under the terms and conditions of the Creative Commons Attribution license (http://creativecommons.org/licenses/by/3.0/). 